\author{
Nathan E. Brummel \\ E. Wesley Ely
}

\section{Sedation level and the prevalence of delirium}

Accepted: 15 August 2013

Published online: 28 August 2013

(C) Springer-Verlag Berlin Heidelberg and ESICM 2013

\section{Dear Editor,}

The study performed by Haenggi and colleagues [1] was needed and helps explore key elements of our lexicon regarding brain dysfunction in critical care medicine. The authors hypothesized that excluding patients who were unable to sustain eye contact for $10 \mathrm{~s}$ or more (RASS-2 or deeper) from receiving a diagnosis of delirium would reduce the prevalence of delirium, which is itself a tautology. The article offers two very important take home points: First, delirium was present in one in three patients who were awake and able to sustain eye contact for $10 \mathrm{~s}$ or more (i.e., RASS- 1 and higher). This is an alarming prevalence of an organ dysfunction that is now a well-established independent predictor of death, length of stay, cost of care, and long-term cognitive impairment. Moreover, these data affirm that the prevalence of delirium in awake ICU patients from earlier studies is accurate [2]. Second, since delirium, especially at a near-normal level of consciousness, is missed $75 \%$ of the time [3], this article offers an excellent reminder that it is important to monitor routinely for delirium using validated instruments such the CAM-ICU or ICDSC.

The vital question raised by this study is this: what might it accomplish to change the cutoff for delirium to RASS-1? Of course, if you don't call something delirium, then there will be less delirium! But to what end? Are the authors trying to reduce the incidence of delirium to avoid unwarranted therapy with antipsychotics? If so, we commend them on this excellent point and reinforce to clinicians that when a patient is delirious, reversible causes should be sought and non-pharmacologic therapies attempted prior to instituting treatment with antipsychotics. Conversely, did the authors consider the much more likely downside that arbitrarily setting "delirium" at a level of consciousness of "sustained eye contact" will propagate the cultural practice of exposing patients to continued use of potentially harmful sedatives since ICU teams will be less inclined to stop sedation in the "absence" of delirium? Under the currently established threshold to detect delirium (established at "no eye contact," a practice in keeping with decades of delirium research and emphasized in the most recent DSMV criteria for delirium), the world's ICU teams will continue to be motivated to reduce and stop sedation because of its obvious contribution to acute brain dysfunction and other adverse outcomes that this therapy causes in our patients [4]. Lastly, there is no indication that sedativeinduced (or the more common scenario of sepsis plus sedation-induced) delirium is any less dangerous than pure sepsis-induced delirium. While further study is needed to answer this question, the current evidence suggests that a sedative-induced altered level of consciousness is not safe and should be avoided when possible. A discussion on daily rounds regarding the patient's current and targeted level of consciousness, sedating medications and delirium status can raise awareness of the role of sedation in the patient's cognitive state, provides an opportunity to discuss both sedation and delirium management plans, and ultimately moves us toward better care.

Acknowledgments Dr. Brummel is supported by the Vanderbilt Clinical and Translational Research Scholars program and by the National Institute on Aging of the NIH under award no. R03AG045095. Dr. Ely is supported by the VA Clinical Science Research and Development Service (VA MERIT Review Award) and the National Institute on Aging of the NIH under award nos. R01AG027472 and R01AG035117.

Conflicts of interest The authors have no relevant financial conflicts of interest to disclose.

\section{References}

1. Haenggi M, Blum S, Brechbuehl R, Brunello A, Jakob SM, Takala J (2013) Effect of sedation level on the prevalence of delirium when assessed with CAMICU and ICDSC. Intensive Care Med. doi:10.1007/s00134-013-3034-5

2. Ely EW, Inouye SK, Bernard GR, Gordon S, Francis J, May L, Truman B, Speroff T, Gautam S, Margolin R, Hart RP, Dittus R (2001) Delirium in mechanically ventilated patients: validity and reliability of the Confusion Assessment Method for the Intensive Care Unit (CAM-ICU). JAMA 286:2703-2710

3. Spronk PE, Riekerk B, Hofhuis J, Rommes JH (2009) Occurrence of delirium is severely underestimated in the ICU during daily care. Intensive Care Med 35:1276-1280

4. Shehabi Y, Bellomo R, Reade MC, Bailey M, Bass F, Howe B, McArthur C, Seppelt IM, Webb S, Weisbrodt L (2012) Early intensive care sedation predicts long-term mortality in ventilated critically ill patients. Am J Respir Crit Care Med 186:724-731

\section{N. E. Brummel (区)}

Department of Medicine, Division of Allergy, Pulmonary and Critical Care Medicine, Vanderbilt School of Medicine, 2525 West End Avenue, Suite 350,

Nashville, TN, USA

e-mail: nathan.brummel@vanderbilt.edu

E. W. Ely

MCE Suite 6000, 1215 21st Ave. South, Nashville, TN 37232, USA 